\title{
Clinical Study \\ Clinical Results after High-Dose Intensity-Modulated Radiotherapy for High-Risk Prostate Cancer
}

\author{
Valérie Fonteyne, ${ }^{1}$ Nicolaas Lumen, ${ }^{2}$ Geert Villeirs, ${ }^{3}$ Piet Ost, ${ }^{1}$ and Gert De Meerleer ${ }^{1}$ \\ ${ }^{1}$ Department of Radiotherapy, Ghent University Hospital, 9000 Ghent, Belgium \\ ${ }^{2}$ Department of Urology, Ghent University Hospital, 9000 Ghent, Belgium \\ ${ }^{3}$ Department of Radiology, Ghent University Hospital, 9000 Ghent, Belgium
}

Correspondence should be addressed to Valérie Fonteyne, valerie.fonteyne@uzgent.be

Received 7 June 2011; Accepted 21 September 2011

Academic Editor: Martin Spahn

Copyright (C) 2012 Valérie Fonteyne et al. This is an open access article distributed under the Creative Commons Attribution License, which permits unrestricted use, distribution, and reproduction in any medium, provided the original work is properly cited.

Purpose. Patients with high-risk prostate cancer (PC) can be treated with high-dose intensity-modulated radiotherapy (IMRT) and long-term androgen deprivation (AD). In this paper we report on (i) late toxicity and (ii) biochemical (bRFS) and clinical relapse-free survival (cRFS) of this combined treatment. Methods. 126 patients with high-risk PC (T3-4 or PSA $>20 \mathrm{ng} / \mathrm{mL}$ or Gleason 8-10) and $\geq 24$ months of followup were treated with high-dose IMRT and AD. Late toxicity was recorded. Biochemical relapse was defined as PSA nadir $+2 \mathrm{ng} / \mathrm{mL}$. Clinical relapse was defined as local failure or metastases. Results. The incidence of late grade 3 gastrointestinal and genitourinary toxicity was 2 and 6\%, respectively. Five-year bRFS and cRFS were 73\% and $86 \%$ respectively. AD was a significant predictor of bRFS $(P=0.001)$ and cRFS $(P=0.01)$. Conclusion. High-dose IMRT and AD for high-risk PC offers excellent biochemical and clinical control with low toxicity.

\section{Introduction}

The of PSA screening has resulted in an increased detection rate of prostate cancer (PC) with stage migration towards lower-stage prostate cancer (PC). Nevertheless, still $12 \%$ of the patients with PC will have locally advanced (T3-4 N0 M0 or Tx N1 M0) or metastatic disease at diagnosis [1]. More aggressive therapies are indicated for these patients as they are at increased risk of PC death [2]. External beam radiotherapy (EBRT) is one of the standard treatment options of choice for those patients. However, when conventional low-dose ( $<72 \mathrm{~Gy})$ EBRT is applied in patients with clinical stage T3-T4 PC, local recurrence rates mount to $30 \%$ at 10 years [3]. Improvement of local control is important as local failure is directly correlated with distant metastasis $[3,4]$ and survival [5]. Extensive evidence exists that high-dose radiotherapy (dose $\geq 74 \mathrm{~Gy}$ ) is superior to conventional dose radiotherapy (dose 64-70 Gy) [6-8]. For high-risk patients, an increase in 5-year biochemical relapse-free survival (bRFS) of 19\% has been reported when increasing the dose from $70 \mathrm{~Gy}$ to $80 \mathrm{~Gy}$ [9]. Zelefsky et al. demonstrated that the rate of positive biopsies after EBRT dropped with 30\% when the dose was increased from $<70.2 \mathrm{~Gy}$ to $>81 \mathrm{~Gy}$ [10]. With modern radiotherapy techniques, such as intensitymodulated radiotherapy (IMRT), dose escalation can safely be performed [11]. Randomized trials support the combined use of EBRT and androgen deprivation (AD) with superior disease-specific and overall survival outcomes in patients with locally advanced-stage or high-risk disease $[12,13]$.

Based on the above-mentioned data, patients with highrisk PC are treated at our institute with high-dose IMRT and 24-36 months of AD. In this paper, we report on

(i) late gastrointestinal (GI) and genitourinary (GU) toxicity,

(ii) biochemical control,

(iii) clinical control

of this combined treatment modality.

\section{Material and Methods}

2.1. Patients. Between December 1998 and March 2011, 604 patients were treated with IMRT as primary therapy 
for prostate cancer at Ghent University Hospital (GUH). Over time 3 different dose levels were initiated as has been previously reported [14, 15]. Between 1996 and 2001, 2 prescriptions were launched: $74 \mathrm{~Gy}$ (74R72) and $76 \mathrm{~Gy}$ (76R74) as median dose to the planning target volume (PTV) of the prostate + seminal vesicles with a hard constraint on maximal rectal dose of 72 and $74 \mathrm{~Gy}$, respectively. In 2002, a third dose escalation level was initiated, in which we treated the PTV to 78 Gy while keeping the maximal rectal dose at 76 Gy (78R76).

High-risk PC was defined as PC with one of the following characteristics: clinical T3-4 or PSA $>20 \mathrm{ng} / \mathrm{mL}$ or Gleason $8-10$. Patients with $\mathrm{pN} 1$ or $\mathrm{cN} 1$ disease were treated within another study protocol [16] and consequently not included in this study. In total $43 \%$ of the patients fulfilled these criteria. Only patients with high-risk PC and a minimal followup of 24 months were considered for this report resulting in a study population of 126 patients: 21 patients in the $74 \mathrm{R} 72$ group, 19 patients in the 76R74 group, and 86 patients in the 78R76 group.

$\mathrm{T}$ stage was determined by digital rectal examination supplemented with magnetic resonance (MR) imaging data. The 2002 American Joint Commission on Cancer staging was used [17]. Lymph node staging was done by CT scan in all cases and in 54 cases by pelvic lymphadenectomy. All patients underwent bone scintigraphy. Except for 10 patients, who refused $\mathrm{AD}$, a luteinizing-hormone releasing hormone (LHRH) analogue was initiated for a period of 2436 months.

A fixed questionnaire was used to register the medical history and pretreatment GU and GI symptoms of each patient.

2.2. Treatment Planning. Details on pretreatment imaging, delineation of clinical target volume (CTV) and organs at risk, expansion of CTV to PTV, treatment planning, criteria for plan acceptance, leaf position optimization, patient preparation, and treatment delivery can be found in our previous work [14]. In brief, the CTV consisted of the prostate and seminal vesicles. None of the patients received elective lymph node irradiation. The PTV was created using a 3-dimensional, isotropic expansion of the CTV of $7 \mathrm{~mm}$. The rectal wall (excluding air and faeces), sigmoid colon, bladder, small bowel, and femoral heads were delineated as organs at risk. Patients were treated with empty rectum and comfortably filled bladder.

The dose was prescribed as the median dose to the PTV. Treatment was delivered using $18 \mathrm{MV}$ photons of an Elekta linear accelerator (Crawley, UK) equipped with a multileaf collimator (MLC) and able to deliver IMRT in a step-and-shoot mode. Since 2009, patients were also treated on a Clinac ix (Varian Medical Systems, Palo Alto, Calif, USA). Until 2009, 3 beams with gantry angles $0^{\circ}, 116^{\circ}$, and $244^{\circ}$ were used [8]. Thereafter, planning was performed with 7 beams (gantry angles: $0^{\circ}, 52^{\circ}, 103^{\circ}, 154^{\circ}, 206^{\circ}, 257^{\circ}$, and $308^{\circ}$ ) or with single arc therapy ( 1 full arc counter clockwise) [18]. First, a fixed couch height and portal imaging procedure (Elekta electronic portal imaging device) was used to correct patient positioning. Thereafter, an ultrasoundbased (SonArray, Zmed, Ashland, USA), prostate positioning was added to correct for prostate positioning. Since 2009, positioning is performed by daily kilovoltage cone beam CT.

2.3. Followup. Patients were seen every 3 months for the first year, biannually until 5 years, and yearly thereafter. A fixed toxicity questionnaire was fulfilled at each visit.

2.4. End Points. Late toxicity was defined as any increase of any GI or GU toxicity lasting more than 3 months after cessation of IMRT or occurring for the first time later than 3 months after the end of IMRT. The grade of late GI (Table 1(a)) and GU toxicity (Table 1(b)) was scored according to an in-house developed scoring system based on the RTOG, SOMA/LENT, and CTC toxicity scorings system $[19,20]$. For each symptom, the maximal toxicity score was registered.

Biochemical relapse was defined according to the Phoenix consensus definition, that is, PSA nadir $+2 \mathrm{ng} / \mathrm{mL}$ [21].

Clinical relapse was defined as local failure (determined on prostate biopsies) or metastases (both lymph node and haematogenous metastasis) detected on imaging (18F-fluorodeoxyglucose positron-emitting tomography/computed tomography and bone scan) performed at the time of biochemical relapse.

Kaplan-Meier statistics were used to report on 5-year bRFS and clinical relapse-free survival (cRFS). Univariate analysis (log-rank test) was used to examine the predictive value of the dose prescription group, Gleason score group (Gleason 6 versus 7 versus 8-10), cT (T1-T2-T3-T4), PSA (PSA $<10 \mathrm{ng} / \mathrm{mL}$ versus PSA: $10-20 \mathrm{ng} / \mathrm{mL}$ versus PSA $\geq$ 20 ), staging by lymphadenectomy ( $\mathrm{pN} 0$ versus $\mathrm{pNx}$ ), and use of AD. Multivariate analysis was performed using Cox regression analysis.

Using Chi-square statistics, the baseline patient-related risk factors were compared for the different prescription groups. A $P$ value of $<0.05$ was considered statistically significant.

Statistical analysis was performed with SPSS version 15.0 software (Chicago, ILL, USA).

\section{Results}

Patient characteristics and planning parameters are shown in Tables 2 and 3, respectively. Significantly fewer patients received $\mathrm{AD}$ in prescription group 74R72 $(P=0.002)$. Except for follow-up time, all other parameters were equally balanced between the different prescription groups. Median followup was 48 months.

3.1. Late Toxicity. Late toxicity was mild. No patient developed grade 4 GI or GU toxicity. The incidence of grade 1-3 late GI and GU toxicity is presented in Table 4 . The crude incidence of late grade $3 \mathrm{GI}$ and GU toxicity was 2 and $6 \%$, respectively. Dose escalation did not result in increased GI or GU toxicity. 
TABle 1: (a) The in-house developed Gastrointestinal toxicity scale, (b) The in-house developed Genitourinary toxicity scale.

(a)

\begin{tabular}{|c|c|c|c|c|}
\hline GI & Grade 1 & Grade 2 & Grade 3 & Grade 4 \\
\hline Abdominal cramps & Present, no therapy & $\begin{array}{l}\text { Peroral therapy, for example, } \\
\text { Spasmolytic }\end{array}$ & IV therapy & Surgery \\
\hline Diarrhea & Present, no therapy & $\begin{array}{l}\text { Peroral therapy, for example, } \\
\text { loperamide }\end{array}$ & IV therapy & Surgery \\
\hline Frequency & Present, no therapy & $\begin{array}{l}\text { Peroral therapy, for example, } \\
\text { loperamide }\end{array}$ & IV therapy & - \\
\hline Mucus loss & Present, no therapy & Need hygienic pads & $\begin{array}{l}\text { Continuous, invasive } \\
\text { therapy }\end{array}$ & Surgery \\
\hline Red blood loss & $\begin{array}{l}\text { No therapy, } \\
\text { frequency }<3 \mathrm{x} / \text { week }\end{array}$ & Frequency $\geq 3 \mathrm{x} /$ week & $\begin{array}{l}\text { Invasive therapy } \\
\text { needed, for example, } \\
\text { laser coagulation }\end{array}$ & $\begin{array}{l}\text { Transfusion } \\
\text { need, surgery }\end{array}$ \\
\hline Urgency & Present, no therapy & Peroral therapy & IV therapy & - \\
\hline Incontinence & Present, no therapy & Need hygienic pads ( $\leq 2 /$ day) & $\begin{array}{l}\text { Need hygienic pads } \\
(>2 / \text { day })\end{array}$ & Surgery \\
\hline Anal pain & Present, no therapy & $\begin{array}{l}\text { Local anesthetic for example, } \\
\text { Xylogel }\end{array}$ & Narcotic analgetica & Surgery \\
\hline
\end{tabular}

(b)

\begin{tabular}{|c|c|c|c|c|}
\hline $\mathrm{GU}$ & Grade 1 & Grade 2 & Grade 3 & Grade 4 \\
\hline Nocturia & $\begin{array}{l}\text { Twice pretherapy, } \\
\text { 2-3 times }\end{array}$ & 4-6 times $(<1 \mathrm{x}$ hour $)$ & $\begin{array}{l}>6 \text { times (more } \\
\text { frequently than } \\
\text { hourly) }\end{array}$ & - \\
\hline Frequency & $\begin{array}{l}\text { Once } / 2 \mathrm{~h} \text {, twice } \\
\text { pretherapy }\end{array}$ & Once/1 h & $\begin{array}{l}\text { Once } / 0.5 \mathrm{~h} \text { (more } \\
\text { frequent than hourly) }\end{array}$ & - \\
\hline Hematuria & Microscopic & Intermittent/moderate & $\begin{array}{l}\text { Frequent, gross } \\
\text { hematuria/minor } \\
\text { surgery needed } \\
\text { (coagulation) }\end{array}$ & $\begin{array}{l}\text { Hemorrhagic } \\
\text { cystitis } \\
\text { requiring } \\
\text { transfusion/ } \\
\text { ulceration/ } \\
\text { necrosis }\end{array}$ \\
\hline Dysuria & $\begin{array}{l}\text { Slight, no } \\
\text { medication }\end{array}$ & $\begin{array}{l}\text { Moderate, requiring local } \\
\text { anesthetic (including bladder } \\
\text { spasm) }\end{array}$ & $\begin{array}{l}\text { Dysuria, regular and } \\
\text { frequent narcotics } \\
\text { needed (including } \\
\text { bladder spasm and } \\
\text { pelvis pain)/severe/ } \\
\text { stenosis/TUR or } \\
\text { dilatation }\end{array}$ & $\begin{array}{l}\text { Bladder } \\
\text { obstruction } \\
\text { not } \\
\text { secondary to } \\
\text { clot passage }\end{array}$ \\
\hline Urgency & $\begin{array}{l}\text { Slight, no } \\
\text { medication }\end{array}$ & $\begin{array}{l}\text { Moderate, requiring local } \\
\text { anesthetic (including bladder } \\
\text { spasm) }\end{array}$ & $\begin{array}{l}\text { Severe requiring local } \\
\text { anesthetic }\end{array}$ & 一 \\
\hline Incontinence & $<$ weekly episodes & $<$ daily episodes & $\begin{array}{l}\text { Pads/undergarments/ } \\
\text { day }\end{array}$ & Refractory \\
\hline
\end{tabular}

3.2. Biochemical Relapse. Twenty-eight patients experienced biochemical relapse resulting in a 5 -year bRFS of $73 \%$ for the whole group. T stage, addition of lymphadenectomy, pretreatment PSA, and Gleason score were not significantly correlated with bRFS. Although not significant, there was a strong trend towards better 5-year bRFS rates with higher radiotherapy doses $(52 \%, 83 \%$, and $76 \%$ for $74 \mathrm{R} 72,76 \mathrm{R} 74$, and 78R76, resp., $P=0.051$ ) (Figure 1).

The association of AD was significantly correlated with 5 -year bRFS (77\% versus 30\%; $P<0.001$ ) (Figure 2).
In multivariate analysis $\mathrm{AD}$ remained a significant predictor of bRFS $(P=0.001)$.

3.3. Clinical Relapse. Fourteen patients had a clinical relapse. Clinical relapses occurred in the lymph nodes $(N=4)$, bone $(n=9)$, or prostate $(n=2)$. One patient had both lymph node and bone metastases at time of clinical relapse. The 5year cRFS was $86 \%$. T stage, addition of lymphadenectomy, pretreatment PSA, and Gleason did not significantly influence cRFS. There was a significant correlation between 5-year 
TABLE 2: Patient's characteristics for all patients and according to prescription group.

\begin{tabular}{|c|c|c|c|c|}
\hline \multirow[t]{2}{*}{ Characteristic } & \multicolumn{3}{|c|}{ Prescription group } & \multirow[b]{2}{*}{$78 \mathrm{R} 76(n=86)$} \\
\hline & All $(n=126)$ & 74R72 $(n=21)$ & $76 \mathrm{R} 74(n=19)$ & \\
\hline Age (years) & $66(41-79)$ & $62(51-76)$ & $65(53-75)$ & $66(41-79)$ \\
\hline Followup (months) & $48(24-132)$ & $60(24-132)$ & $84(24-108)$ & $45(24-96)$ \\
\hline PSA level (ng/mL) & $19(4-302)$ & $26(8-150)$ & $20(4-90)$ & $14(4-302)$ \\
\hline \multicolumn{5}{|l|}{ Gleason score } \\
\hline $2-6$ & $49(39)$ & $9(43)$ & $11(58)$ & $29(34)$ \\
\hline $7(3+4) /(4+3)$ & $37(29)$ & $7(33)$ & $5(26)$ & $25(29)$ \\
\hline $8-10$ & $39(31)$ & $5(24)$ & $3(16)$ & $31(36)$ \\
\hline Unknown & $1(1)$ & - & - & $1(1)$ \\
\hline \multicolumn{5}{|l|}{ Tumor stage } \\
\hline $\mathrm{T} 1$ & $17(13)$ & $2(10)$ & $4(20)$ & $11(12)$ \\
\hline $\mathrm{T} 2$ & $40(32)$ & $9(43)$ & $2(11)$ & $29(34)$ \\
\hline $\mathrm{T} 3$ & $60(48)$ & $7(33)$ & $12(64)$ & $40(48)$ \\
\hline $\mathrm{T} 4$ & $9(7)$ & $3(14)$ & $1(5)$ & $6(6)$ \\
\hline \multicolumn{5}{|l|}{ Node stage } \\
\hline pNo & $54(43)$ & $9(43)$ & $3(16)$ & $42(49)$ \\
\hline \multicolumn{5}{|l|}{ Androgen deprivation } \\
\hline Yes & $116(92)$ & $14(67)$ & $17(89)$ & 85 (99) \\
\hline No & $10(8)$ & $7(33)$ & $2(11)$ & $1(1)$ \\
\hline
\end{tabular}

TABLE 3: Planning parameters for all patients and according to prescription. CTV: clinical target volume; Gy: Gray; PTV: planning target volume; R40 and R60: percentage of the rectal volume receiving a dose of 40 and $60 \mathrm{~Gy}$, respectively; $\mathrm{R}_{\text {mean }}$ : mean dose to the rectum, $\mathrm{B}_{\text {max }}$ and $\mathrm{B}_{\text {mean }}$ : maximal and mean dose to the bladder.

\begin{tabular}{|c|c|c|c|c|}
\hline & All $(n=126)$ & $74 \mathrm{R} 72(n=21)$ & 76R74 $(n=19)$ & 78R76 $(n=86)$ \\
\hline CTV volume (cc) & $61(22-180)$ & $86(26-146)$ & $68(28-112)$ & $53(22-180)$ \\
\hline Minimum CTV dose (Gy) & $73(55-77)$ & $68(55-70)$ & $72(67-74)$ & $73(68-77)$ \\
\hline Median CTV dose (Gy) & $78(72-83)$ & $76(72-78)$ & $77(72-82)$ & $79(74-83)$ \\
\hline PTV volume (cc) & $155(48-347)$ & $250(121-347)$ & $226(100-289)$ & $123(48-296)$ \\
\hline Minimum PTV dose (Gy) & $69(52-73)$ & $65(52-68)$ & $67(65-70)$ & $69(64-73)$ \\
\hline Median PTV dose (Gy) & $77(70-82)$ & $74(70-76)$ & $75(72-80)$ & $78(75-82)$ \\
\hline $\mathrm{R} 40$ & $71(30-97)$ & $90(88-90)$ & 87 (57-97) & $68(30-94)$ \\
\hline R60 & $43(22-90)$ & $64(29-90)$ & $54(26-69)$ & $40(22-63)$ \\
\hline $\mathrm{R}_{\text {mean }}$ & $51(33-71)$ & $57(39-65)$ & $54(37-62)$ & $49(33-71)$ \\
\hline $\mathrm{B}_{\max }$ & $79(72-82)$ & $78(72-79)$ & $79(76-82)$ & $79(76-82)$ \\
\hline $\mathrm{B}_{\text {mean }}$ & $43(13-72)$ & $49(19-68)$ & $58(16-65)$ & $40(13-72)$ \\
\hline
\end{tabular}

TABLE 4: Late gastrointestinal and genitourinary toxicity for all patients and according to prescription group.

\begin{tabular}{|c|c|c|c|c|}
\hline \multicolumn{5}{|c|}{ Late GI toxicity } \\
\hline & All $(n=126)$ & $74 \mathrm{R} 72(n=21)$ & $76 \mathrm{R} 74(n=19)$ & $78 \mathrm{R} 76(n=86)$ \\
\hline Grade 1 & $52(41)$ & $9(43)$ & $8(42)$ & $35(41)$ \\
\hline Grade 2 & $20(16)$ & $6(29)$ & $2(11)$ & $12(14)$ \\
\hline Grade 3 & $2(2)$ & 0 & $1(5)$ & $1(1)$ \\
\hline \multicolumn{5}{|c|}{ Late GU toxicity } \\
\hline & All $(n=126)$ & $74 \mathrm{R} 72(n=21)$ & $76 \mathrm{R} 74(n=19)$ & $78 \mathrm{R} 76(n=86)$ \\
\hline Grade 1 & $55(44)$ & $11(52)$ & $7(37)$ & $37(43)$ \\
\hline Grade 2 & $26(21)$ & $1(5)$ & $4(21)$ & $21(24)$ \\
\hline Grade 3 & $7(6)$ & $3(14)$ & $1(5)$ & $3(4)$ \\
\hline
\end{tabular}




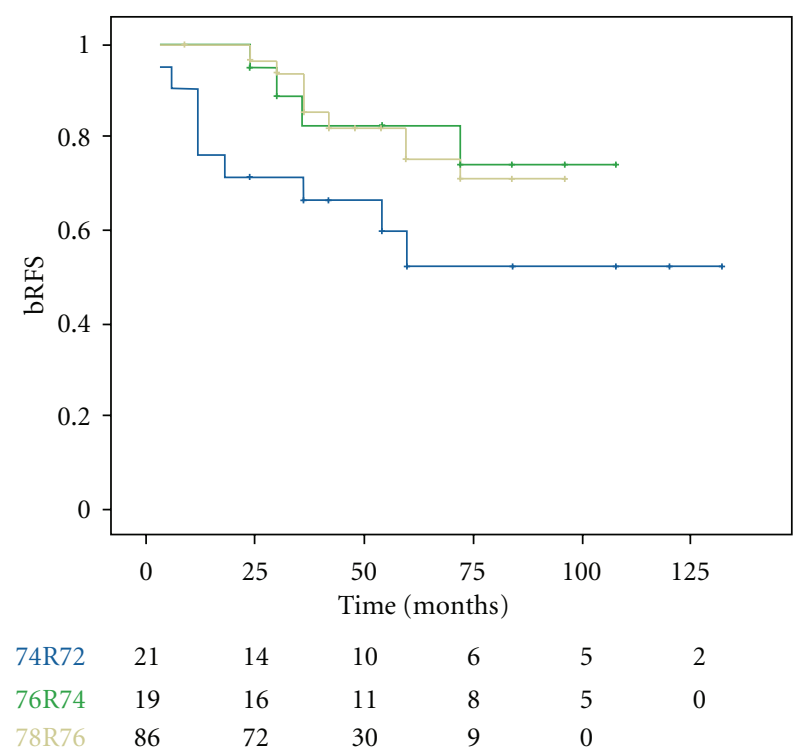

FIGURE 1: Biochemical relapse-free survival according to prescription group.

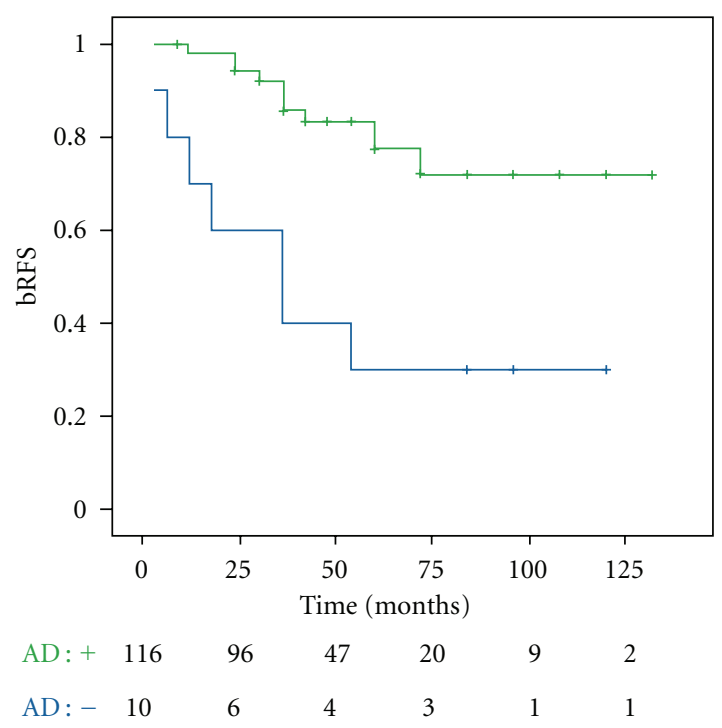

FIGURE 2: Biochemical relapse-free survival for patients treated with high-dose IMRT with or without androgen deprivation.

cRFS and dose $(67 \%, 83 \%$, and $90 \%$ for $74 \mathrm{R} 72,76 \mathrm{R} 74$, and 78R76, resp.; $P=0.04$ ) as well as between 5-year cRFS and $\mathrm{AD}(91 \%$ versus $30 \% ; P<0.001)$.

The only significant predictor of cRFS in multivariate analysis was $\mathrm{AD}(P=0.01)$.

\section{Discussion}

Multiple treatment options are available for patients with high-risk PC such as surgery, high-dose EBRT, and AD.

$\mathrm{AD}$ has been the primary treatment for patients with high-risk PC for many years. Although the response rate is high, $\mathrm{AD}$ alone is not a curative therapy and has important side effects. A recently published randomized trial confirmed that the addition of EBRT to AD resulted in a significant improvement in overall survival when compared to $\mathrm{AD}$ [22].

Merglen et al. claimed that surgery, as a single treatment, offers the best 10-year survival rates for T1-T3 PC patients when compared to EBRT without AD, particularly for younger patients and patients with poorly differentiated tumours [23]. However this study has major shortcomings such as the lack of information on radiation dose and an imbalance between the surgery and radiotherapy group concerning Gleason score and PSA [23]. Moreover, 10year overall survival and PC-specific survival was better for patients treated with EBRT and AD versus prostatectomy alone $(80 \%$ versus $69 \%$ and $87 \%$ versus $83 \%$ for overall survival and PC-specific survival, resp.).

Akakura et al. randomized patients between radical prostatectomy and low-dose EBRT (60-70 Gy) both combined with $\mathrm{AD}$. The 10-year overall survival rates were better for the surgery group, although not statistically significant [24]. Recently the long-term outcome of patients with highrisk PC was reported comparing survival after RP and EBRT $\pm \mathrm{AD}$. The authors concluded that RP and EBRT $+\mathrm{AD}$ provided similar long-term cancer control for patients with high-risk PC [25]. In a retrospective matched case analysis, $\mathrm{RP}$, brachytherapy, and multimodality radiotherapy (i.e., EBRT with brachytherapy boost and AD) were compared. Significantly improved bRFS at 4 years was reported with multimodality radiotherapy (multimodality radiotherapy: 72\%, brachytherapy: 25\%, and RP: 53\%, $P<0.001$ ) [26]. In the absence of randomized trials and based on published data surgery, whether or not combined with adjuvant radiotherapy and high-dose radiotherapy combined with $\mathrm{AD}$ should be considered as equally effective in this patient group.

In the published series, clinical or biochemical relapse is still observed in more than a quarter of the patients 5 years after treatment. Extensive evidence exists that highdose radiotherapy (dose $\geq 74 \mathrm{~Gy}$ ) is superior to conventional dose radiotherapy (dose 64-70 Gy). Zelefsky et al. reported long-term results after high-dose radiotherapy for T3 PC. For patients treated with high doses (81 Gy) combined with $\mathrm{AD}, 5$ - and 10-year PSA relapse-free survival was $77 \%$ and $52 \%$ for T3a stage and $53 \%$ and $49 \%$ for T3b stage PC. Dose was an important predictor of improved biochemical control. With higher doses ( $\geq 81 \mathrm{~Gy}), 5$ - and 10-year local progression-free survival of $96 \%$ and $88 \%$ is reported [27].

Our data confirm these encouraging figures with 5-year bRFS and cRFS rates of $73 \%$ and $86 \%$, respectively. In contrast with the study of Zelefsky et al., we were not able to detect a significant dose-response relationship. Although there was a significant relation between prescription dose and cRFS and a strong trend towards better bRFS with higher doses, this was no longer present in multivariate analysis. These data must be interpreted with caution due to the small number of patients in the lowest prescription group as well as the imbalance between the patients receiving $\mathrm{AD}$ in the different prescription groups. Significantly fewer patients in prescription group 74R72 received $\mathrm{AD}$. The role of concomitant $\mathrm{AD}$ was unequivocally confirmed in our 
study with a significant impact on bRFS and cRFS in uniand multivariate analysis.

Dose escalation to the prostate is only defendable if both radiotherapy-induced GI and GU toxicities remain acceptable. There is level 1 evidence that toxicity increases with dose when conventional or conformal radiation technologies are used [11]. The implementation of new radiotherapy technologies has resulted in low GI toxicity rates. Even with dose escalation to the prostate late grade $\geq 3$ GI toxicity is rare with modern radiotherapy techniques with incidence rates of $<1 \%$ [28] to $2 \%$ [29] and $5 \%$ [30]. On the contrary, GU toxicity is more frequent with incidence rates of late grade $\geq 3$ GU toxicity of $13 \%$ [30]. The reported toxicity rates in our study (grade 3 GI: $2 \%$ and grade 3 GU: $6 \%$ ) are comparable with published data and confirm that highdose IMRT combined with AD can safely be delivered. Dose escalation did not result in higher toxicity rates in our study probably as a result of the implementation of a direct aperture and weight optimization (SOWAT) in the higher prescription groups. In a planning study, the use of SOWAT resulted in a reduction of the rectal complication probability by lowering the physical dose to rectal volumes without compromising the dose to the prostate. The present paper confirms that SOWAT is clinically relevant and makes further dose escalation possible without increasing rectal or urinary toxicity.

The role of prophylactic pelvic irradiation for patients with high-risk PC is still under debate. Two large randomised trials were published with opposite results. The Radiation Therapy Oncology Group (RTOG) 9413 trial favours pelvic radiotherapy [31]. A significant 7\% improvement in the 4year progression-free survival (PFS) rate was reported when patients were treated with a combination of neoadjuvant + concurrent $\mathrm{AD}$ and pelvic EBRT compared with prostatealone EBRT for patients with intermediate and high-risk PC. However, there was no significant benefit in overall or distant metastases-free survival. Importantly, an increase in late grade 2 and 3 toxicities was noted [31].

The GETUG randomised trial on the contrary failed to show differences in PFS [32].

There are 2 important shortcomings of these "older" trials that might have influenced the results: at first, the radiotherapy dose to the prostate was low (70 Gy). Secondly there might have been an insufficient coverage of the pelvic lymph nodes regions at risk. The role of dose was evaluated in the GETUG trial in which they failed to show a significant difference in the groups receiving $<$ or $\geq 70$ Gy at the level of the prostate, which is, after all, still a low dose [32].

A large retrospective study with high-dose brachytherapy also failed to demonstrate a benefit for pelvic irradiation, suggesting that dose escalation to the prostate rather than pelvic radiotherapy is beneficial [33].

A new phase III trial (RTOG 0924) will soon be opened for enrolment further addressing the issue on prophylactic pelvic irradiation. The RTOG 0924 is a phase III trial for intermediate and favourable high-risk PC patients randomizing between androgen deprivation and high-dose radiotherapy with or without whole pelvic radiotherapy. PIVOTAL is another multicentre study for patients with locally advanced PC randomising between high-dose IMRT to the prostate \pm pelvic lymph nodes. The endpoints of the study are toxicity, quality of life, and disease outcome. Patient recruitment is now ongoing.

In the absence of the results of these "modern" phase III trials, the implementation of pelvic irradiation is not current standard and left at the discretion of the radiotherapists. In our study only 4 patients had a clinical relapse in the lymph nodes making the omission of prophylactic pelvic radiotherapy defendable certainly when taking into account the increased risk of GI toxicity as a result of irradiation of larger volumes of small bowel, even with modern radiotherapy techniques.

Some recent data suggest that the patient's outcome is positively influenced by staging lymphadenectomy. However, the exact impact of an extended lymphadenectomy on patient outcomes has not yet been clearly determined. Recently, Masterson et al. reported that a higher number of nodes removed correlated significantly with bRFS in men without nodal involvement [34] probably as a result of elimination of micrometastases that are not detected by routine histological examination. Joslyn and Konety [35] published similar results. Patients included in this study were treated since 1996. At that time staging lymphadenectomies were not routinely performed. Consequently only few patients in our study received a staging pelvic lymphadenectomy. Moreover, there is an important lack of information on extent of lymphadenectomy and number of lymph nodes removed. In our study 3 of the 4 patients presenting with lymph node relapse did not have previous lymphadenectomy.

\section{Conclusion}

High-dose IMRT and AD for high-risk PC offers excellent biochemical and clinical control with low toxicity.

\section{References}

[1] A. L. Moore, P. Dimitropoulou, A. Lane et al., "Populationbased prostate-specific antigen testing in the UK leads to a stage migration of prostate cancer," BJU International, vol. 104, no. 11, pp. 1592-1598, 2009.

[2] M. S. Anscher, R. Clough, and R. Dodge, "Radiotherapy for a rising prostate-specific antigen after radical prostatectomy: the first 10 years," International Journal of Radiation Oncology Biology Physics, vol. 48, no. 2, pp. 369-375, 2000.

[3] J. J. Coen, A. L. Zietman, H. Thakral, and W. U. Shipley, "Radical radiation for localized prostate cancer: local persistence of disease results in a late wave of metastases," Journal of Clinical Oncology, vol. 20, no. 15, pp. 3199-3205, 2002.

[4] P. B. Morgan, A. L. Hanlon, E. M. Horwitz, M. K. Buyyounouski, R. G. Uzzo, and A. Pollack, "Radiation dose and late failures in prostate cancer," International Journal of Radiation Oncology Biology Physics, vol. 67, no. 4, pp. 1074-1081, 2007.

[5] R. Jacob, A. L. Hanlon, E. M. Horwitz, B. Movsas, R. G. Uzzo, and A. Pollack, "The relationship of increasing radiotherapy dose to reduced distant metastases and mortality in men with prostate cancer," Cancer, vol. 100, no. 3, pp. 538-543, 2004.

[6] D. P. Dearnaley, M. R. Sydes, J. D. Graham et al., "Escalateddose versus standard-dose conformal radiotherapy in prostate 
cancer: first results from the MRC RT01 randomised controlled trial," The Lancet Oncology, vol. 8, no. 6, pp. 475-487, 2007.

[7] A. Pollack, G. K. Zagars, G. Starkschall et al., "Prostate cancer radiation dose response: results of the M. D. Anderson phase III randomized trial," International Journal of Radiation Oncology Biology Physics, vol. 53, no. 5, pp. 1097-1105, 2002.

[8] A. L. Zietman, K. Bae, J. D. Slater et al., "Randomized trial comparing conventional-dose with high-dose conformal radiation therapy in early-stage adenocarcinoma of the prostate: long-term results from proton radiation oncology group/american college of radiology 95-09," Journal of Clinical Oncology, vol. 28, no. 7, pp. 1106-1111, 2010.

[9] G. A. Viani, E. J. Stefano, and S. L. Afonso, "Higher-thanconventional radiation doses in localized prostate cancer treatment: a meta-analysis of randomized, controlled trials," International Journal of Radiation Oncology Biology Physics, vol. 74, no. 5, pp. 1405-1418, 2009.

[10] M. J. Zelefsky, V. E. Reuter, Z. Fuks, P. Scardino, and A. Shippy, "Influence of local tumor control on distant metastases and cancer related mortality after external beam radiotherapy for prostate cancer," Journal of Urology, vol. 179, no. 4, pp. 13681373, 2008.

[11] D. P. Dearnaley, V. S. Khoo, A. R. Norman et al., "Comparison of radiation side-effects of conformal and conventional radiotherapy in prostate cancer: a randomised trial," The Lancet, vol. 353, no. 9149, pp. 267-272, 1999.

[12] M. V. Pilepich, K. Winter, C. A. Lawton et al., "Androgen suppression adjuvant to definitive radiotherapy in prostate carcinoma-long-term results of phase III RTOG 85-31," International Journal of Radiation Oncology Biology Physics, vol. 61, no. 5, pp. 1285-1290, 2005.

[13] M. Bolla, L. Collette, L. Blank et al., "Long-term results with immediate androgen suppression and external irradiation in patients with locally advanced prostate cancer (an EORTC study): a phase III randomised trial," The Lancet, vol. 360, no. 9327, pp. 103-108, 2002.

[14] G. O. de Meerleer, V. H. Fonteyne, L. Vakaet et al., "Intensitymodulated radiation therapy for prostate cancer: late morbidity and results on biochemical control," Radiotherapy and Oncology, vol. 82, no. 2, pp. 160-166, 2007.

[15] V. Fonteyne, G. Villeirs, B. Speleers et al., "Intensitymodulated radiotherapy as primary therapy for prostate cancer: report on acute toxicity after dose escalation with simultaneous integrated boost to intraprostatic lesion," International Journal of Radiation Oncology Biology Physics, vol. 72, no. 3, pp. 799-807, 2008.

[16] V. Fonteyne, W. de Gersem, W. de Neve et al., "Hypofractionated intensity-modulated arc therapy for lymph node metastasized prostate cancer," International Journal of Radiation Oncology Biology Physics, vol. 75, no. 4, pp. 1013-1020, 2009.

[17] American Joint Committee on Cancer, "Prostate," in AJCC Cancer Staging Manual, 6th edition, pp. 309-316, Springer, New York, NY, USA, 2002.

[18] P. Ost, B. Speleers, G. de Meerleer et al., "Volumetric arc therapy and intensity-modulated radiotherapy for primary prostate radiotherapy with simultaneous integrated boost to intraprostatic lesion with 6 and $18 \mathrm{MV}$ : planning comparison study," International Journal of Radiation Oncology Biology Physics, vol. 79, no. 3, pp. 920-926, 2011.

[19] V. Fonteyne, G. Villeirs, N. Lumen, and G. de Meerleer, "Urinary toxicity after high dose intensity modulated radiotherapy as primary therapy for prostate cancer," Radiotherapy and Oncology, vol. 92, no. 1, pp. 42-47, 2009.
[20] V. Fonteyne, W. de Neve, G. Villeirs, C. de Wagter, and G. de Meerleer, "Late radiotherapy-induced lower intestinal toxicity (RILIT) of intensity-modulated radiotherapy for prostate cancer: the need for adapting toxicity scales and the appearance of the sigmoid colon as co-responsible organ for lower intestinal toxicity," Radiotherapy and Oncology, vol. 84, no. 2, pp. 156-163, 2007.

[21] M. Roach III, G. Hanks, H. Thames Jr. et al., "Defining biochemical failure following radiotherapy with or without hormonal therapy in men with clinically localized prostate cancer: recommendations of the RTOG-ASTRO Phoenix Consensus Conference," International Journal of Radiation Oncology Biology Physics, vol. 65, no. 4, pp. 965-974, 2006.

[22] A. Widmark, O. Klepp, A. Solberg et al., "Endocrine treatment, with or without radiotherapy, in locally advanced prostate cancer (SPCG-7/SFUO-3): an open randomised phase III trial," The Lancet, vol. 373, no. 9660, pp. 301-308, 2009.

[23] A. Merglen, F. Schmidlin, G. Fioretta et al., "Short- and longterm mortality with localized prostate cancer," Archives of Internal Medicine, vol. 167, no. 18, pp. 1944-1950, 2007.

[24] K. Akakura, H. Suzuki, T. Ichikawa et al., "A randomized trial comparing radical prostatectomy plus endocrine therapy versus external beam radiotherapy plus endocrine therapy for locally advanced prostate cancer: results at median follow-up of 102 months," Japanese Journal of Clinical Oncology, vol. 36, no. 12, pp. 789-793, 2006.

[25] S. A. Boorjian, R. J. Karnes, R. Viterbo et al., "Long-term survival after radical prostatectomy versus external-beam radiotherapy for patients with high-risk prostate cancer," Cancer, vol. 117, no. 13, pp. 2883-2891, 2011.

[26] S. G. Fletcher, S. E. Mills, M. E. Smolkin, and D. Theodorescu, "Case-Matched comparison of contemporary radiation therapy to surgery in patients with locally advanced prostate cancer," International Journal of Radiation Oncology Biology Physics, vol. 66, no. 4, pp. 1092-1099, 2006.

[27] M. J. Zelefsky, Y. Yamada, M. A. Kollmeier, A. M. Shippy, and M. A. Nedelka, "Long-term outcome following threedimensional conformal/intensity-modulated external-beam radiotherapy for clinical stage T3 prostate cancer," European Urology, vol. 53, no. 6, pp. 1172-1179, 2008.

[28] M. J. Zelefsky, E. J. Levin, M. Hunt et al., "Incidence of late rectal and urinary toxicities after three-dimensional conformal radiotherapy and intensity-modulated radiotherapy for localized prostate cancer," International Journal of Radiation Oncology Biology Physics, vol. 70, no. 4, pp. 1124-1129, 2008.

[29] A. L. Zietman, M. L. DeSilvio, J. D. Slater et al., "Comparison of conventional-dose vs high-dose conformal radiation therapy in clinically localized adenocarcinoma of the prostate: a randomized controlled trial," Journal of the American Medical Association, vol. 294, no. 10, pp. 1233-1239, 2005.

[30] S. T. H. Peeters, W. D. Heemsbergen, P. C. M. Koper et al., "Dose-response in radiotherapy for localized prostate cancer: results of the Dutch multicenter randomized phase III trial comparing 68 Gy of radiotherapy with 78 Gy," Journal of Clinical Oncology, vol. 24, no. 13, pp. 1990-1996, 2006.

[31] C. A. Lawton, M. DeSilvio, M. Roach III et al., "An update of the phase III trial comparing whole pelvic to prostate only radiotherapy and neoadjuvant to adjuvant total androgen suppression: updated analysis of RTOG 94-13, with emphasis on unexpected hormone/radiation interactions," International Journal of Radiation Oncology Biology Physics, vol. 69, no. 3, pp. 646-655, 2007. 
[32] P. Pommier, S. Chabaud, J. L. Lagrange et al., "Is there a role for pelvic irradiation in localized prostate adenocarcinoma? Preliminary results of GETUG-01," Journal of Clinical Oncology, vol. 25, no. 34, pp. 5366-5373, 2007.

[33] C. E. Vargas, R. Galalae, J. Demanes et al., "Lack of benefit of pelvic radiation in prostate cancer patients with a high risk of positive pelvic lymph nodes treated with high-dose radiation," International Journal of Radiation Oncology Biology Physics, vol. 63, no. 5, pp. 1474-1482, 2005.

[34] T. A. Masterson, F. J. Bianco Jr., A. J. Vickers et al., "The association between total and positive lymph node counts, and disease progression in clinically localized prostate cancer," Journal of Urology, vol. 175, no. 4, pp. 1320-1324, 2006.

[35] S. A. Joslyn and B. R. Konety, "Impact of extent of lymphadenectomy on survival after radical prostatectomy for prostate cancer," Urology, vol. 68, no. 1, pp. 121-125, 2006. 


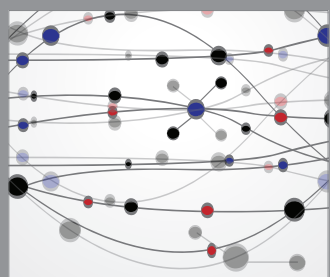

The Scientific World Journal
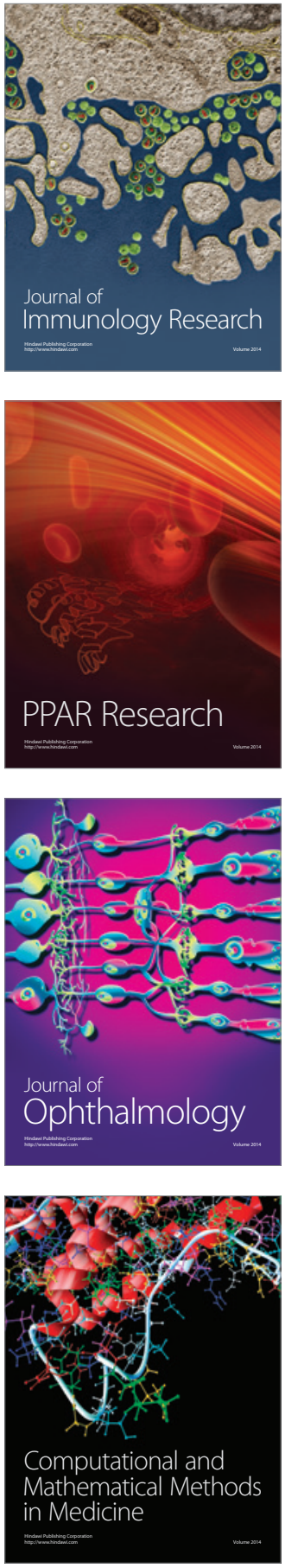

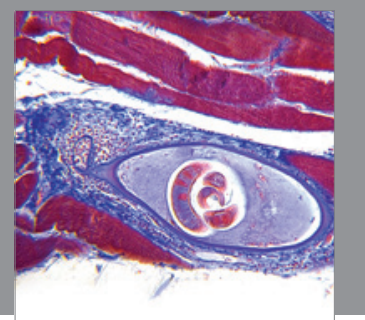

Gastroenterology

Research and Practice
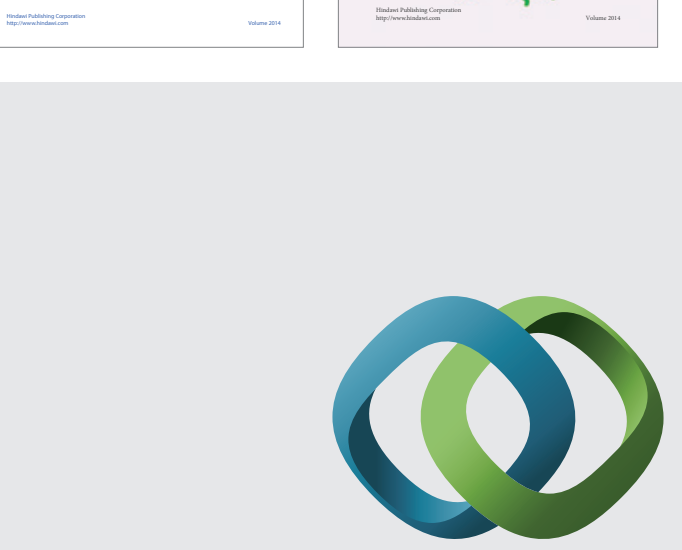

\section{Hindawi}

Submit your manuscripts at

http://www.hindawi.com
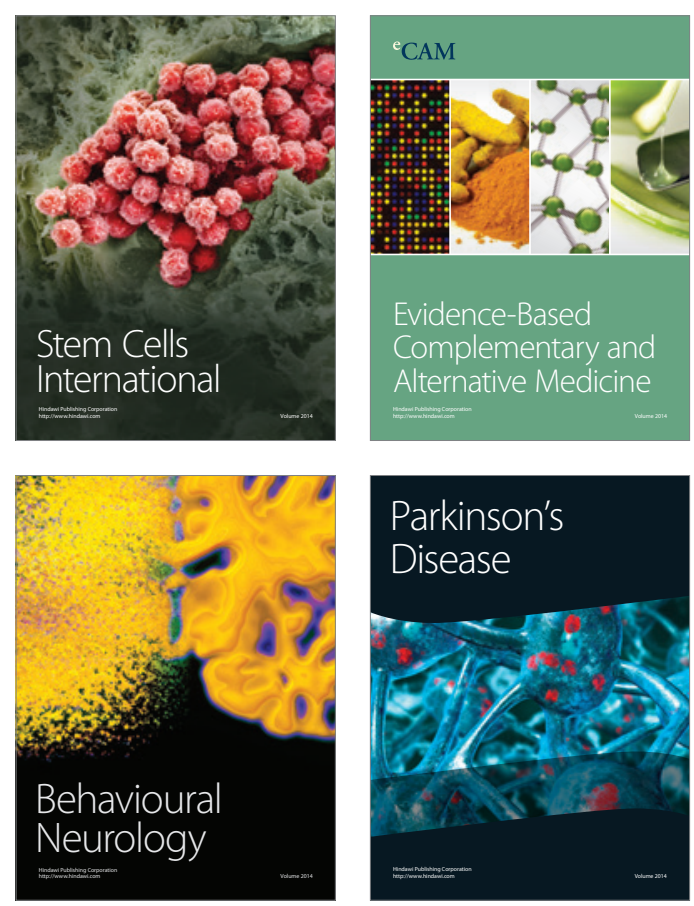

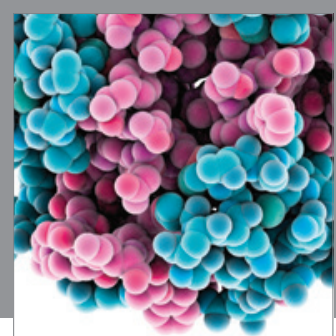

Journal of
Diabetes Research

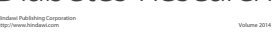

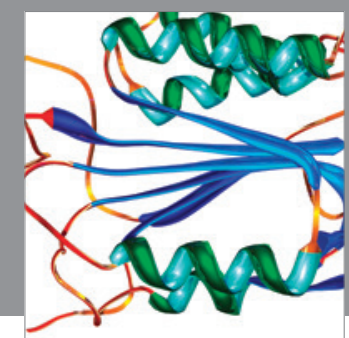

Disease Markers
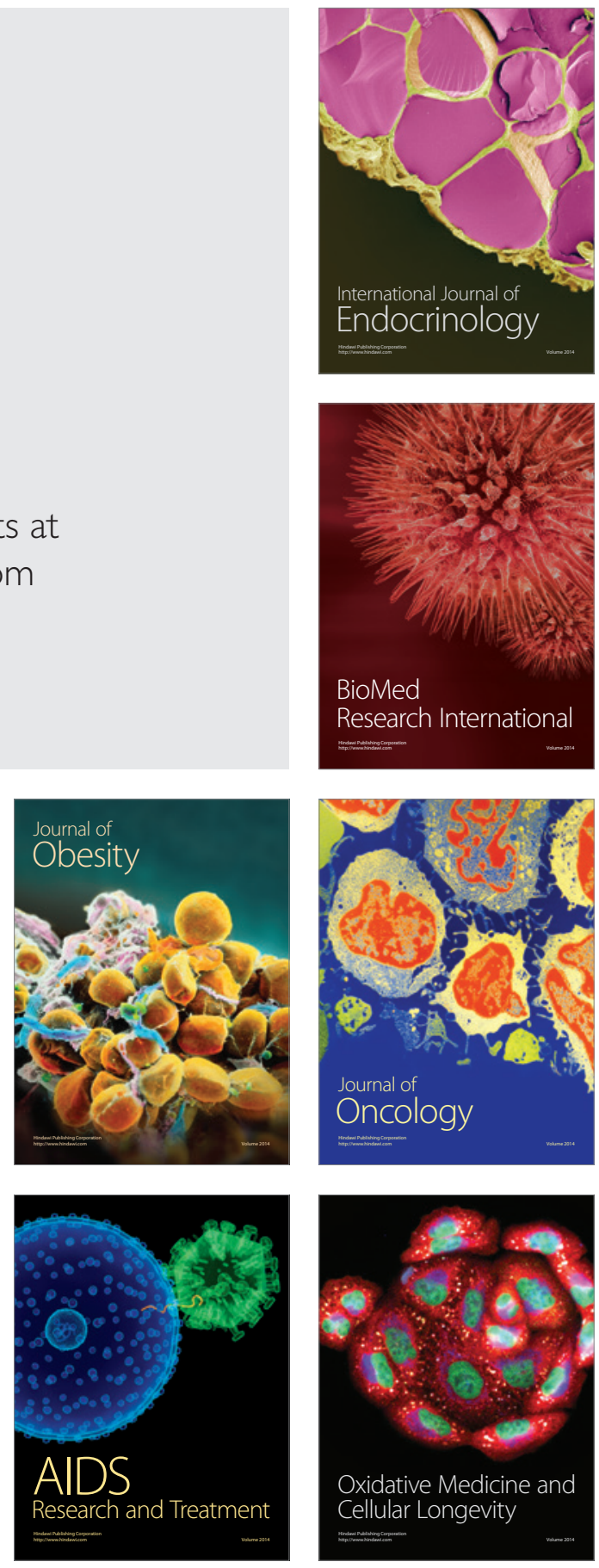